\title{
Enemigos naturales y control biológico ${ }^{1}$
}

\author{
Hugh A. Smith y John L. Capinera, traducido por Ana Lucrecia MacVean²
}

Esta publicación también está disponible en Inglés: ENY822 Natural Enemies and Biological Control (this publication is also available in English: ENY-822 Natural Enemies and Biological Control).

\section{Bichos buenos y malos}

Cualquier organismo que se alimenta de otro es conocido como su enemigo natural. Los insectos que son enemigos naturales de plagas se llaman insectos benéficos. Otros artrópodos tales como arañas y algunos ácaros también son benéficos.

Existen dos principales tipos de artrópodos benéficos, los depredadores y los parasitoides. Los depredadores, como por ejemplo las mariquitas y arañas, atacan a diversos tipos de insectos y consumen diversas presas en el transcurso de su ciclo de vida. Los parasitoides son moscas o avispas que depositan sus huevecillos sobre o dentro de otros artrópodos; a éstos se les llama parásitos. El huevecillo revienta y el parasitoide inmaduro se alimenta de su víctima, llamado hospedero, y eventualmente lo mata.

Los insectos también sufren de enfermedades. Estas enfermedades, conocidas como entomopatógenos, son microorganismos que atacan a los insectos e incluyen bacterias, hongos, virus y nemátodos. Con pocas excepciones, las enfermedades que atacan a los artrópodos no causan daño a otros animales tales como mamíferos y pájaros. A veces se utilizan insectos y patógenos de plantas para controlar malezas.

\section{Control biológico de plagas}

El control biológico es un enfoque usado para reducir las poblaciones de insectos dañinos con enemigos naturales. A organismos introducidos de otras partes del mundo se les conoce como exóticos comparado con los organismos nativos o propios del lugar. Plagas pueden ser introducidas a Estados Unidos de América y establecerse sin enemigos naturales que las mantenga bajo control. El control biológico de organismos exóticos involucra encontrar a los enemigos naturales de la plaga e introducirlos al área en donde la plaga exótica ya se haya establecido. En Florida actualmente hay intentos para manejar plagas exóticas tales como el grillo topo o la hierba acuática Hydrilla. Todos los enemigos naturales exóticos deben ser estudiados cuidadosamente antes de su liberación para que no causen un impacto negativo ambiental o económico.

La efectividad tanto de enemigos naturales nativos como introducidos puede ser mejorada a través de la propagación masiva de insectos benéficos para su posterior liberación (aumento masivo) o por la modificación del ambiente para favorecer a depredadores y parasitoides (conservación). Muchos insectos benéficos pueden adquirirse en empresas de crianza comerciales para luego ser liberados masivamente. Las mariquitas/tortolitas así como crisopas son ejemplos de algunos depredadores que pueden ser comprados en las empresas de crianza y que ayudan a controlar áfidos, mosca blanca así como otras plagas. Los parasitoides de mosca blanca, huevos de orugas

1. Este documento, ENY-866, es uno de una serie de publicaciones del Entomology and Nematology, Servicio de Extensión Cooperativa de la Florida, Instituto de Alimentos y Ciencias Agrícolas, Universidad de la Florida. (UF/IFAS). Fecha de primera publicación: January 2013. Visite nuestro sitio web EDIS en <http://edis.ifas.ufl.edu>.

2. Hugh A. Smith, assistant professor, y John L. Capinera, profesor y director, Departmento de Entomología y Nematología; Servicio de Extensión Cooperativa, Instituto de Ciencias Agrícolas y de Alimentos Universidad de Florida, Gainesville, FL 32611. Traducido por Ana Lucrecia MacVean, Herbario PAC, Pennsylvania State University. 
así como otras plagas se pueden también comprar para liberación posterior en granjas, invernaderos o jardines y huertos. Adicionalmente, algunos entomopatógenos están disponibles comercialmente en formulaciones y se pueden aplicar como pesticidas. El ejemplo más común es Bacillus thuringiensis $(\mathrm{Bt})$, una bacteria disponible en diversas variedades las cuales producen compuestos tóxicos para ciertos grupos de insectos.

La conservación usualmente involucra el establecimiento de plantas que provean una fuente alternativa de alimento, tal como el néctar y el polen el cual es utilizado por los insectos benéficos; la conservación también implica el uso selectivo de insectidas para que no dañen a especies benéficas. Muchos insectos benéficos se alimentan del polen de plantas tales como cilantro, anís y trigo sarraceno. Puede ser posible aumentar el número de insectos benéficos al incluir estas plantas en los jardines o los cultivos. Pesticidas como el Bt matan a orugas causando una mínima disrupción de los enemigos naturales, permitiendo así que los agricultores y jardineros se beneficien del control biológico natural.

\section{Manejo integrado de plagas (MIP)}

El control de plagas es usualmente más efectivo cuando se usa como un componente del sistema de manejo integrado de plagas (MIP). MIP involucra el uso de una variedad de técnicas económicamente viables y ambientalmente concientes para manejar a una plaga. Los programas de MIP dependen de una inspección periódica de los cultivos para determinar si las poblaciones de plagas están llegando a niveles de daño. A esto se le llama plagueo o monitoreo (scouting en inglés), lo cual adicionalmente da información sobre cuál es la proporción relativa de artrópodos benéficos y dañinos en un cultivo. Los programas efectivos de monitoreo conllevan una significativa reducción en el uso de pesticidas porque éstos solamente son aplicados cuando son necesarios. La reducción en el uso de pesticidas es la preocupación central de la mayoría de los programas de MIP, y es crucial para optimizar el control biológico ya que muchos enemigos naturales son altamente susceptibles a pesticidas. Cuando el uso de pesticidas aumenta, la población de enemigos naturales disminuye. Los programas de MIP dependen de un cuidadoso uso de pesticidas selectivos tales como el Bt y se benefician con el aumento de la efectividad de enemigos naturales tanto nativos como exóticos/introducidos.

\section{Algunos buenos insectos (benéficos) comúnmente vistos en Florida}

Hay muchos insectos benéficos pero solamente hay algunos que son enemigos naturales de plagas. Los enemigos naturales más comunes de encontrar son: mariquitas/ tortolitas, crisopas, antocóridos (Orius), ligaéidos, sírfidos, avispas de agallas, hormigas, avispas parasíticas, moscas parasíticas y ácaros depredadores. La importancia relativa varía de acuerdo con cada insecto plaga, el hábitat y la estación o época del año.

\section{Mariquitas/tortolitas}

Los adultos de las mariquitas ("lady beetles" en inglés) (Figura 1) son uno de los insectos fácilmente reconocibles, sobre todo cuando son los escarabajos típicos-naranja con manchas negras. Muchas personas no se percatan de que estos insectos tienen diversos colores incluyendo el rojo, café o el negro y que usualmente carecen de manchas
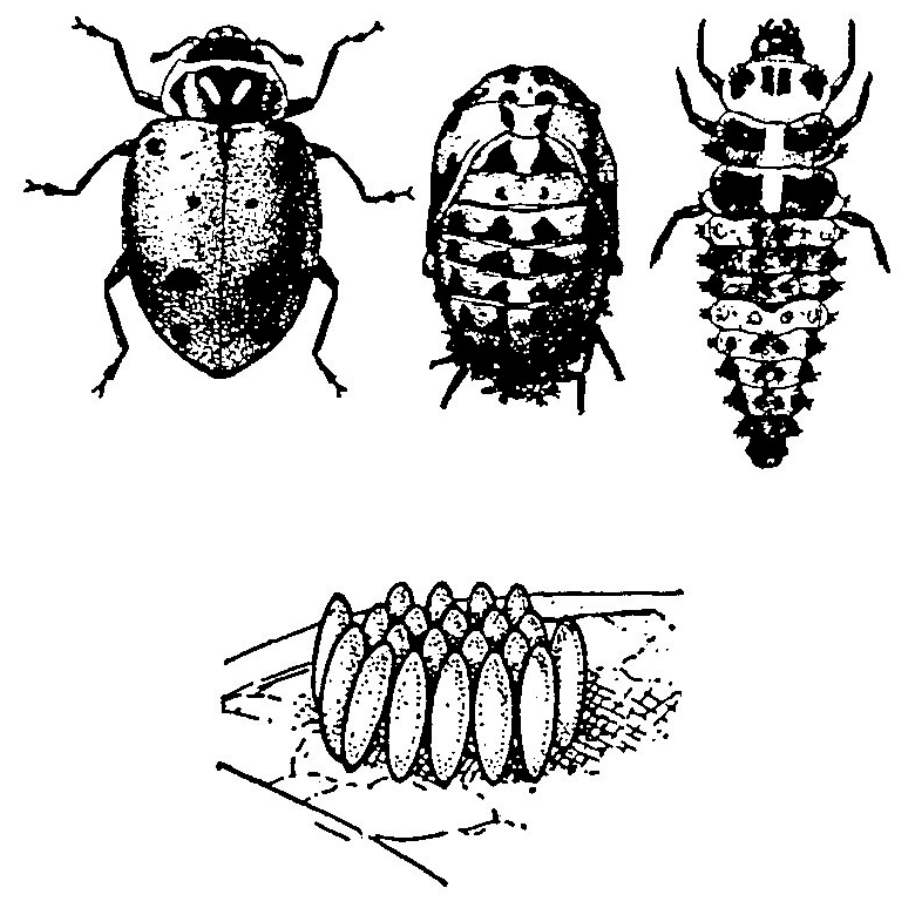

Figure 1. Estadíos de la mariquita común: adulto, pupa y larva (arriba), un conjunto de huevecillos (abajo).

Credits: U. S. Department of Agriculture

(puntos) negros. La forma hemisférica de los adultos es un carácter importante así como el comportamiento de búsqueda frenética-siempre están en busca de qué comer-ayuda a identificar a las mariquitas. Las larvas son más difíciles de reconocer, y muchos jardineros las matan en su etapa benéfica de inmadurez ya que las desconocen y no saben identificar esta etapa en el insecto. Las larvas son 
generalmente elongadas, aplanadas y usualmente negruzcas o azuladas con manchas/puntos anaranjados.

En el estado de Florida una especie común de mariquita tiene una larva con un exudado blanco y ceroso en la parte dorsal. Si usted ve un insecto blanquecino moviéndose entre áfidos, es muy probable que sea una larva de mariquita. El color de la pupa es similar a la larva, sin embargo la pupa es incapaz de moverse o de alimentarse. Los huevecillos amarillos son depositados en grupos. Las mariquitas se alimentan de numerosos insectos pequeños y atacan cualquier estadío de presa que sea lo suficiente pequeño. Se encuentran más frecuentemente entre colonias de áfidos pero también pueden consumir ácaros, escamas, cochinillas, moscas blancas, pequeñas orugas y pequeñas larvas de escarabajos así como cualquier tipo de huevecillo de insectos.

\section{Crisopas}

Tanto las crisopas verdes como las cafés (Figura 2) ocurren en Florida y los bellos adultos con alas que parecen encaje son fácilmente reconocibles. Al igual que las mariquitas, las crisopas (conocidas como lacewings en inglés) usualmente
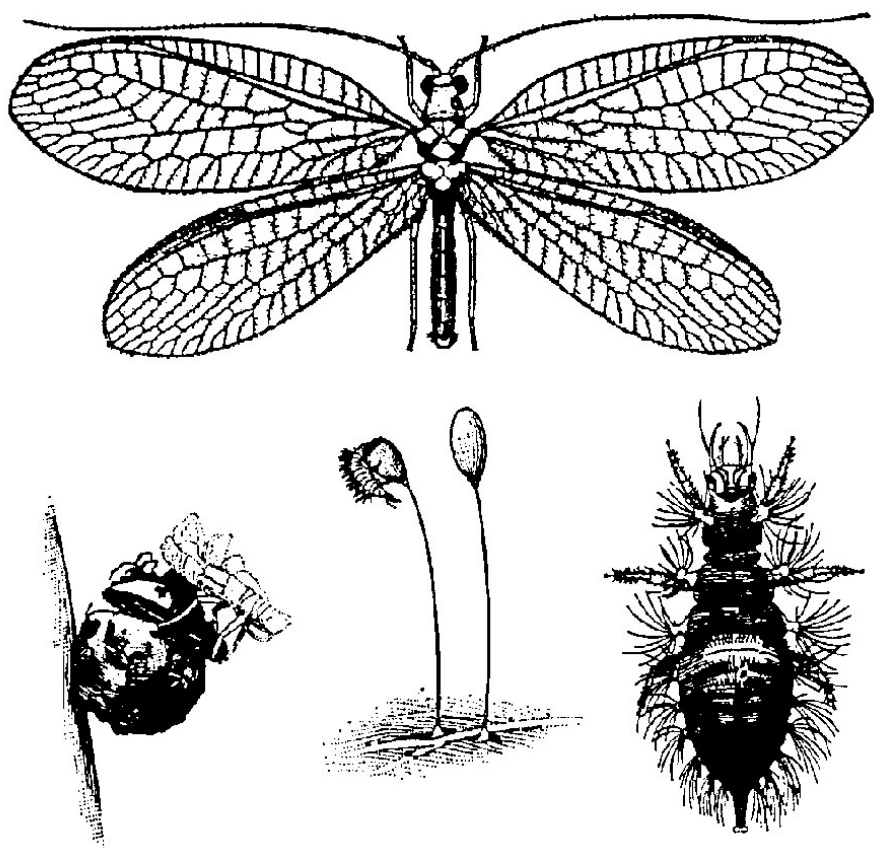

Figure 2. Crisopa adulto (arriba). Una crisopa emergiendo de una pupa, emergiendo de un huevo y una larva (abajo).

Credits: U. S. Department of Agriculture

se encuentran asociadas con colonias de áfidos. Sin embargo, en contraste con las mariquitas, los adultos muchas veces no se alimentan de insectos, siendo solamente la larva, la que es el estadío benéfico. Las grandes piezas bucales en forma de guadaña, que son aparentes cuando estan en estado larvario, son muy eficientes para adherirse a su presa y drenarle fluídos corporales. Los huevecillos de las crisopas son depositados en largos tallos y distribuidos en grupos. Las crisopas se alimentan de huevecillos de insectos, escamas, cochinillas, acáros así como de áfidos.

\section{Sírfidos}

Los sírfidos ("flower flies" en inglés) (Figura 3) son insectos de color amarillo y negro que se parecen a abejas mielíferas. Como el nombre en inglés sugiere, usualmente se encuentran sobrevolando cerca o alimentándose de flores.

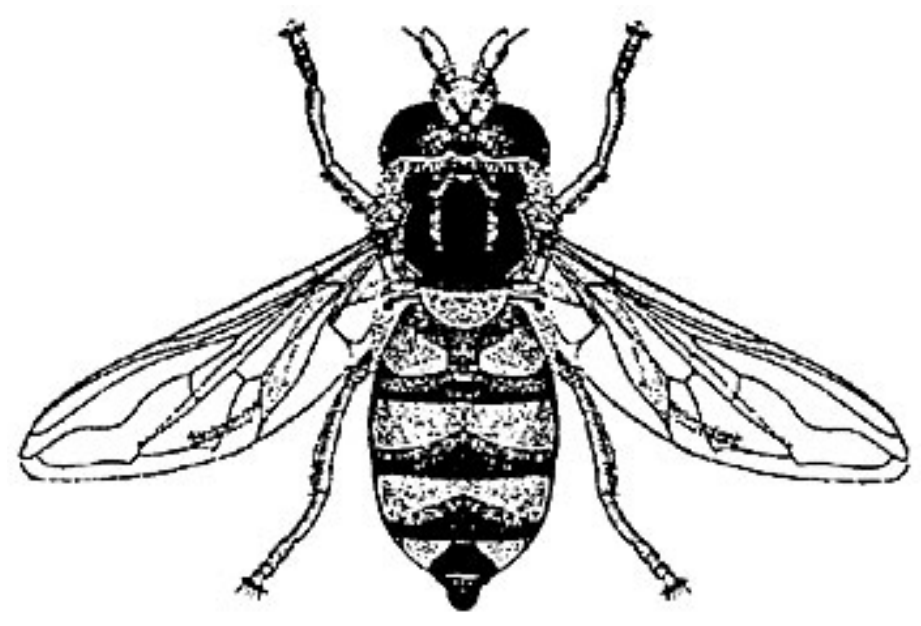

Figure 3. Típico sírfido, adulto.

Credits: U. S. Department of Agriculture

Sin embargo las larvas son voraces depredadores y son especialmente atraídas a áfidos (Figura 4). Las larvas tienen apariencia de gusano con un cuerpo grueso que se estrecha a una cabeza puntiaguda. Pueden ser amarillentas, rojizas o verduzcas.

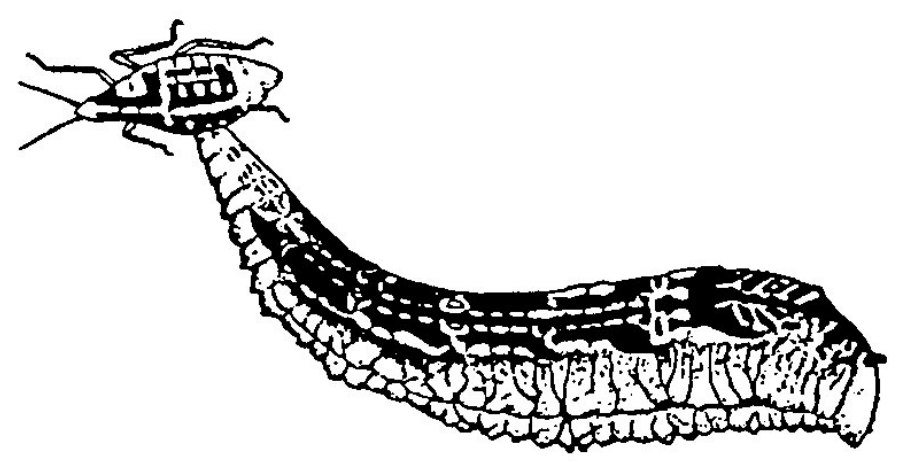

Figure 4. Una larva de sírfido alimentándose de un áfido. Credits: U. S. Department of Agriculture 


\section{Mosquita depredadora/cecidomíido}

Las larvas de las mosquitas depredadores (conocidos en inglés como "predatory gall midges") (Figura 5) se parecen a los sírfidos y usualmente pasan por alto porque son muy pequeñas. Muchas personas, si observan las larvas, piensan que son sírfidos muy jóvenes. Comúnmente se encuentran entre las colonias de áfidos pero también se alimentan de moscas blancas, escamas, thrips y ácaros. Sin embargo los adultos son completamente diferentes. El adulto de las mosquitas, que casi nunca se observa porque es activo sólo en la noche, es pequeño, pálido y tiene patas delgadas y largas; no se puede confundir con un sírfido adulto!

\section{Geocóridos}

Este depredador común (conocido en inglés como "bigeyed bug") (Figura 6) se encuentra usualmente en sistemas agrícolas. Ambos el adulto y su estadío inmaduro se reconocen por sus enormes ojos ya que por lo demás son insectos indefinidos grísaceos y pequeños. El aparato bucal punzante chupador es usado para drenar fluidos de los huevecillos de palomillas, orugas, thrips y ácaros.

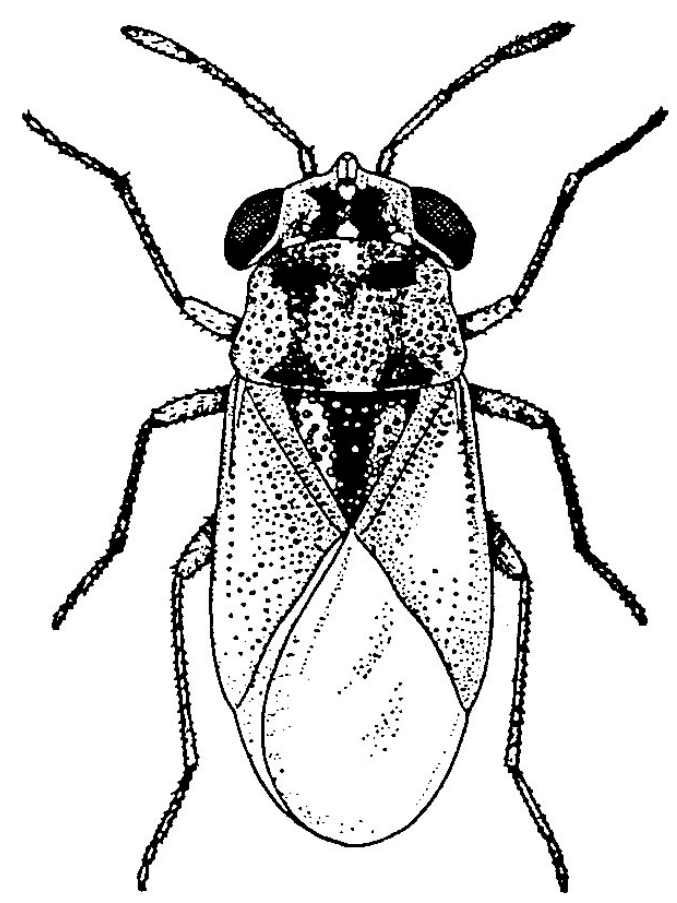

Figure 6. Geocórido adulto.

Credits: U. S. Department of Agriculture

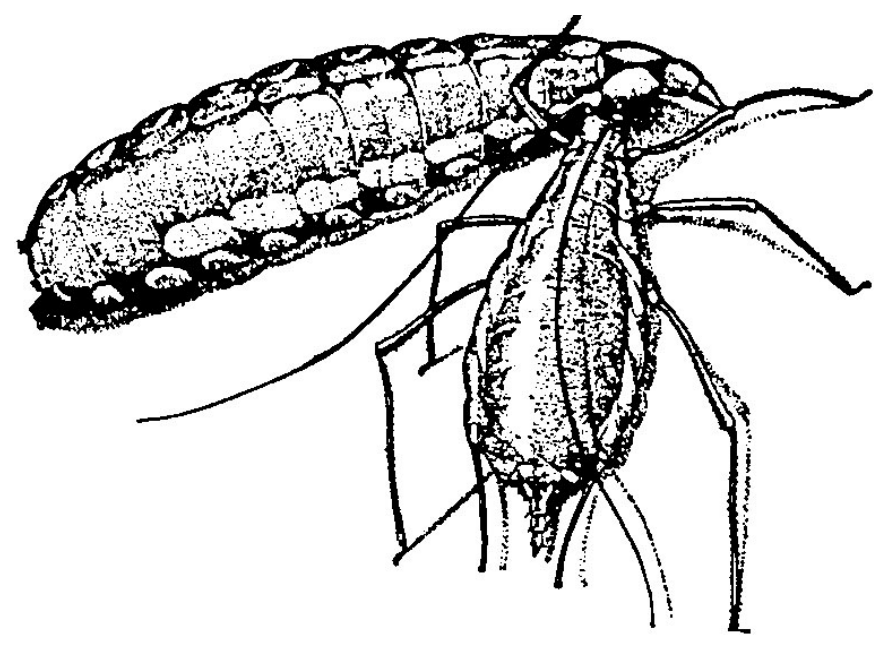

Figure 5. Estadío de larva de unmosco depredador cecidomíido del género Aphidoletes, alimentándose de un áfido.

Credits: U. S. Department of Agriculture

\section{Antocóridos}

Estos insectos muy pequeños (conocidos como "minute pirate bugs" en inglés) son fácilmente pasados por alto pero su importancia como insecto benéfico no puede ser sobrestimada. Al igual que los geocóridos se alimentan vorazmente utilizando su aparato bucal punzante chupador para drenar fluidos de insectos como psocidos, saltahojas, áfidos, thrips y ácaros. Los adultos (Figura 7) son blanco plateado y negro. Ocurren por todos lados incluyendo entre cultivos.

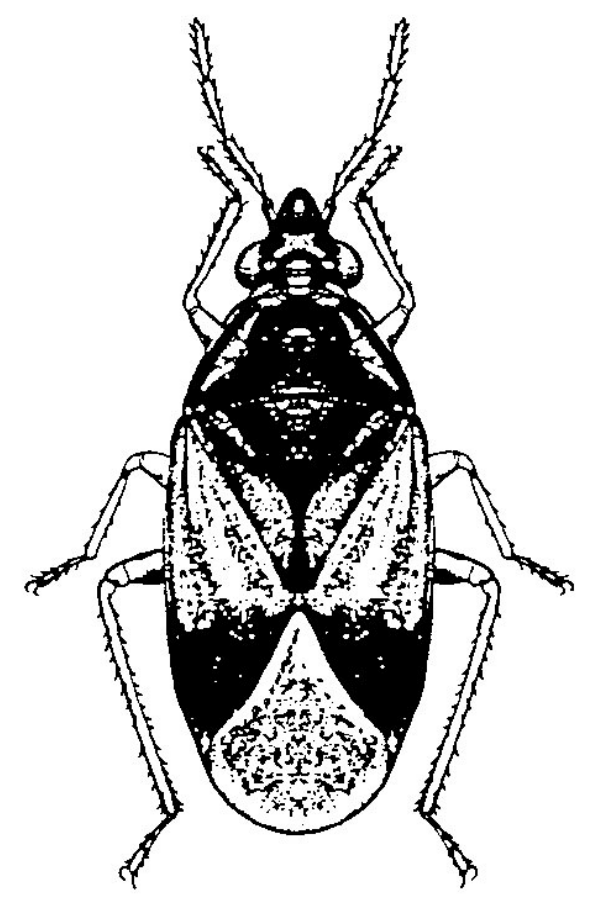

Figure 7. Antocórido adulto.

Credits: U. S. Department of Agriculture 


\section{Chinches olorosas}

Chinches olorosas (llamadas en inglés "soldier bugs" o "stink bugs") son conocidas como plagas serias así como depredadores benéficos porque diversas especies varían en cuanto a sus hábitos alimenticios. La chinche olorosa más común en Florida, la chinche olorosa verde de las hortalizas (southern green stink bug en inglés) ataca flores y frutos causando deformidades y caída de la fruta.

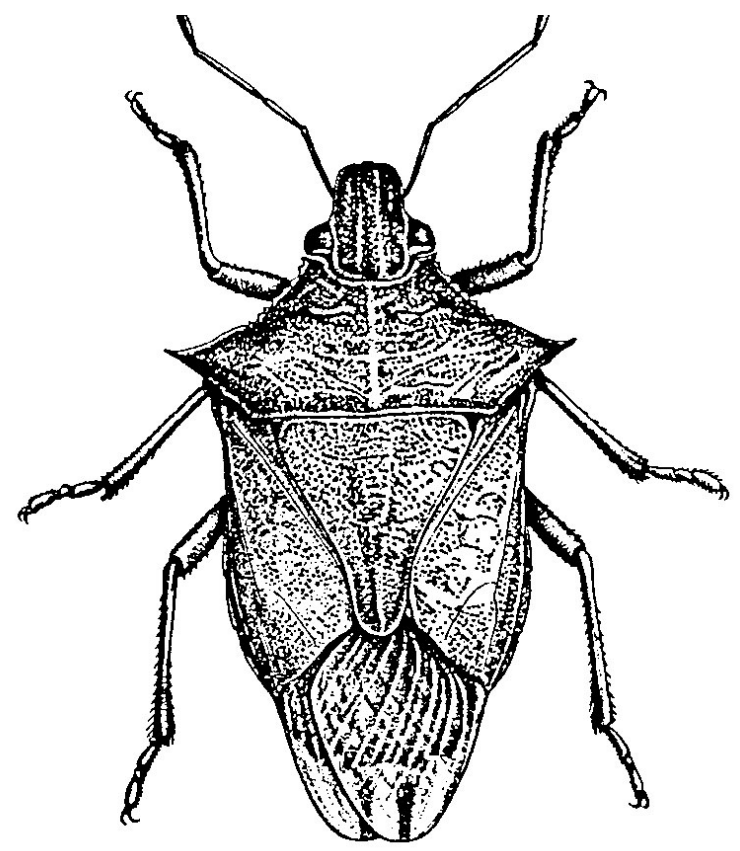

Figure 8. Chinche olorosa depredadora, adulto.

Credits: U. S. Department of Agriculture

¿Cómo se puede distinguir entre chinches benéficas o dañinas? Todas las chinches tienen un aparato bucal punzante chupador que es largo, delgado y tubular. Los insectos benéficos utilizan sus partes bucales para extraer fluidos de otros insectos, particularmente orugas y larvas de escarabajos. Los insectos dañinos utilizan sus partes bucales para extraer savia de las plantas. Las partes bucales de las chinches olorosas son relativamente fuertes mientras que las de las plagas son delgadas y frágiles. Si tiene duda, debe observar el comportamiento del insecto antes de decidir si es o no dañino.

\section{Hormigas}

Muchas personas usualmente se sorprenden de saber que algunas hormigas son depredadores importantes. Aún las hormigas coloradas o también llamadas hormigas bravas ("fire ants" en inglés) (Figura 9) pueden ser útiles para reducir el número de insectos plaga. Agricultores que tienen problemas con hormigas coloradas muy raras veces tienen también problemas con orugas o cualquier otro insecto plaga de cuerpo blando! Las hormigas sin embargo no son del todo benéficas, y además de su tendencia de morder o picar, las hormigas también protegen de depredadores y parasitismo a insectos que producen excreciones azucaradas tales como escamas y áfidos. Así que las hormigas son una bendición a medias dependiendo de qué tipo de planta o plaga están presentes.

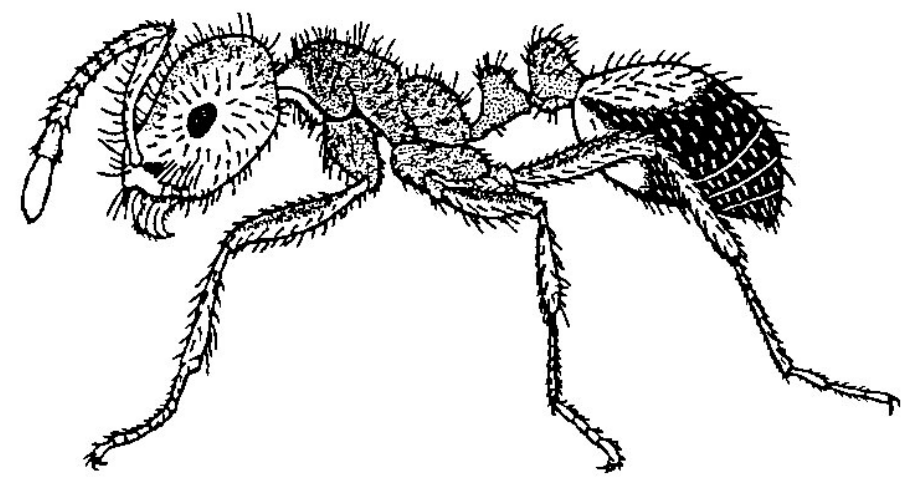

Figure 9. Hormiga colorada importada, una especie de hormiga depredadora común.

Credits: U. S. Department of Agriculture

\section{Avispas parasíticas}

La mayoría de avispas parasíticas ("parasitic wasps" en inglés) son pequeñas e inconspicuas, sin embargo ellas parasitan a huevecillos de insectos que son aún más pequeños, casi microscópicos en tamaño. Por lo tanto, agricultores y jardineros por lo regular ignoran el hecho que parasitoides están ayudando a controlar sus plagas. Algunas veces estas avispas pueden ser vistas caminando rápidamente sobre la superficie de la hoja de una planta golpeando sus antenas en busca del "olor" de un hospedero. Las avispas parasíticas depositan sus huevecillos en el insecto hospedero (Figura 10 y 11)-usualmente en el hospedero que se encuentra en estado de huevo o de larva.

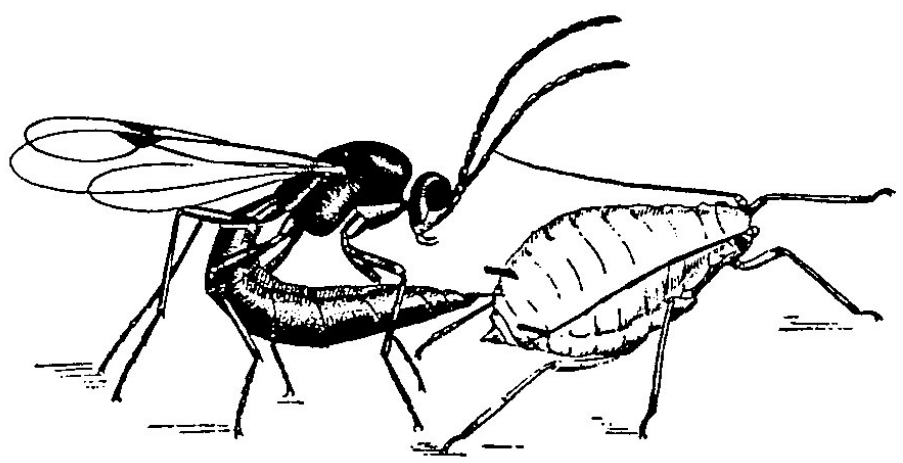

Figure 10. Una avispa parasítica depositando su huevecillo dentro de un áfido.

Credits: U. S. Department of Agriculture 


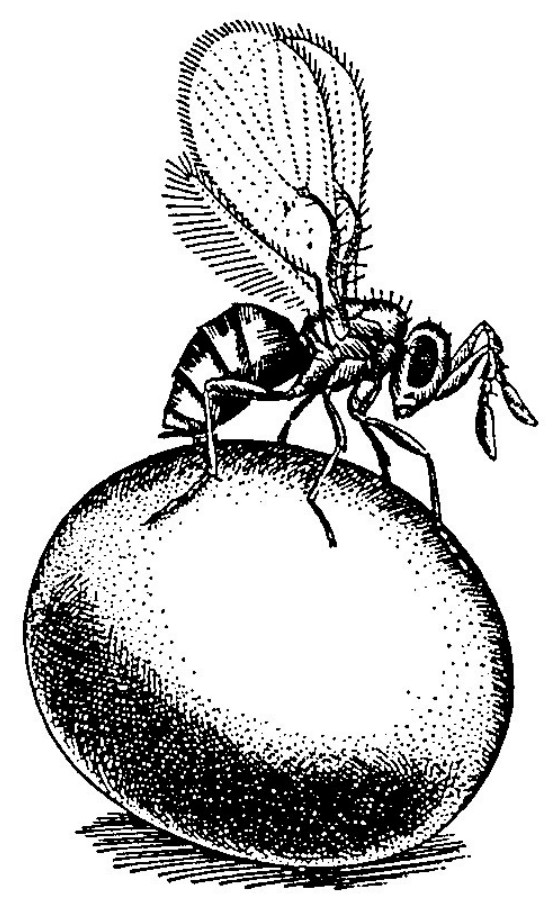

Figure 11. Una avispa del género Trichogramma depositando su huevecillo dentro de un huevo de palomilla.

Credits: U. S. Department of Agriculture

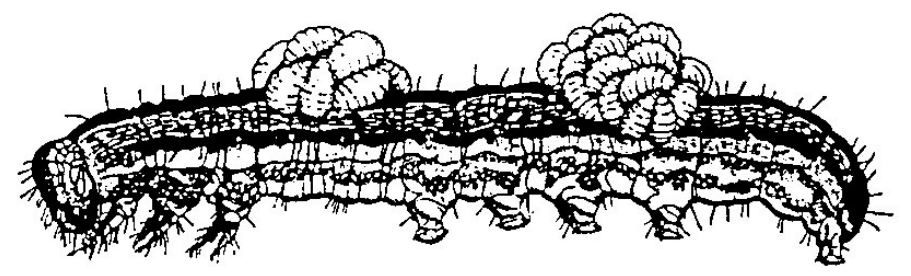

Figure 12. Grupos de larvas de avispa parasítica desarrollándose externamente sobre una oruga.

Credits: U. S. Department of Agriculture

El parásito joven se desarrolla dentro o en el hospedero (Figura 12) eventualmente matándolo. La evidencia más común de parasitismo es usualmente una oruga moribunda de la cual están saliendo larvas de parasitoide, o una oruga muerta en la cual el cuelga un cocón. Las avispas parasíticas son importantes enemigos naturales de orugas, gusanos, mosca blanca y áfidos.

\section{Moscas parasíticas}

Varios tipos de moscas parasíticas ("parasitic flies" en inglés) (Figura 13) atacan a plagas. Muchas depositan sus huevos en la superficie de la plaga; cuando la larva emerge ésta cava dentro de la plaga y eventualmente la mata. Otras depositan sus larvas dentro del hospedero, con el mismo resultado. Sin embargo, las moscas parasíticas carecen de una estructura larga para depositar huevos que es común en muchas avispas.

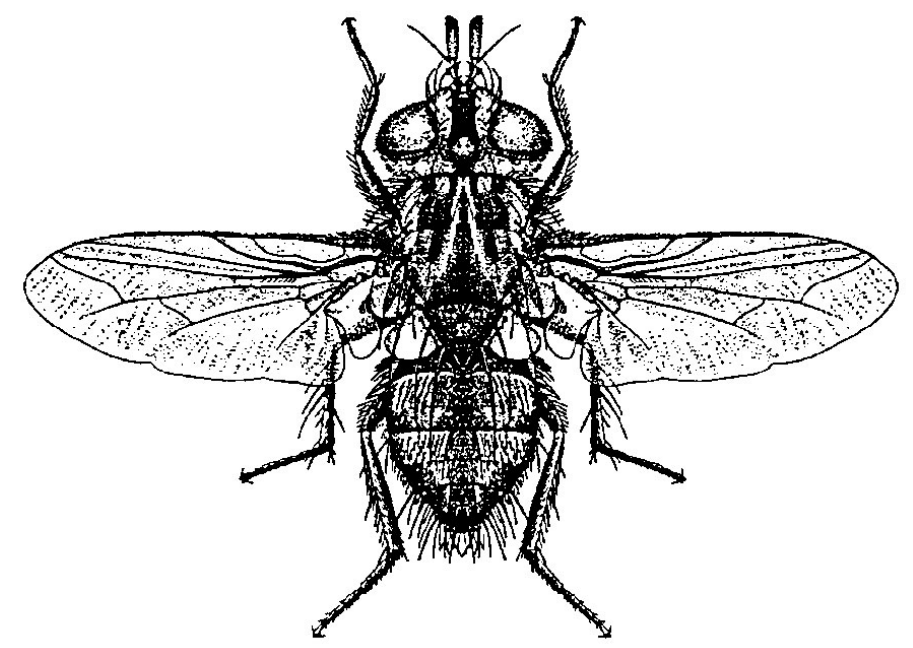

Figure 13. Adulto de una mosca parasítica. Credits: U. S. Department of Agriculture

\section{Acaros depredadores}

A pesar de que algunos ácaros son conocidos como plagas serias de plantas, muchos ácaros son benéficos. Dentro de los ácaros benéficos, los fitoseídos son especialmente importantes debido a que son depredadores de ácaros que se alimentan de plantas, así como de otros organismos tales como thrips o huevecillos de insectos. Los ácaros depredadores ("predatory mites" en inglés) (Figura 14) tienden a ser más grandes que otros ácaros, tener patas más alargadas y se mueven más activamente en busca de una presa.

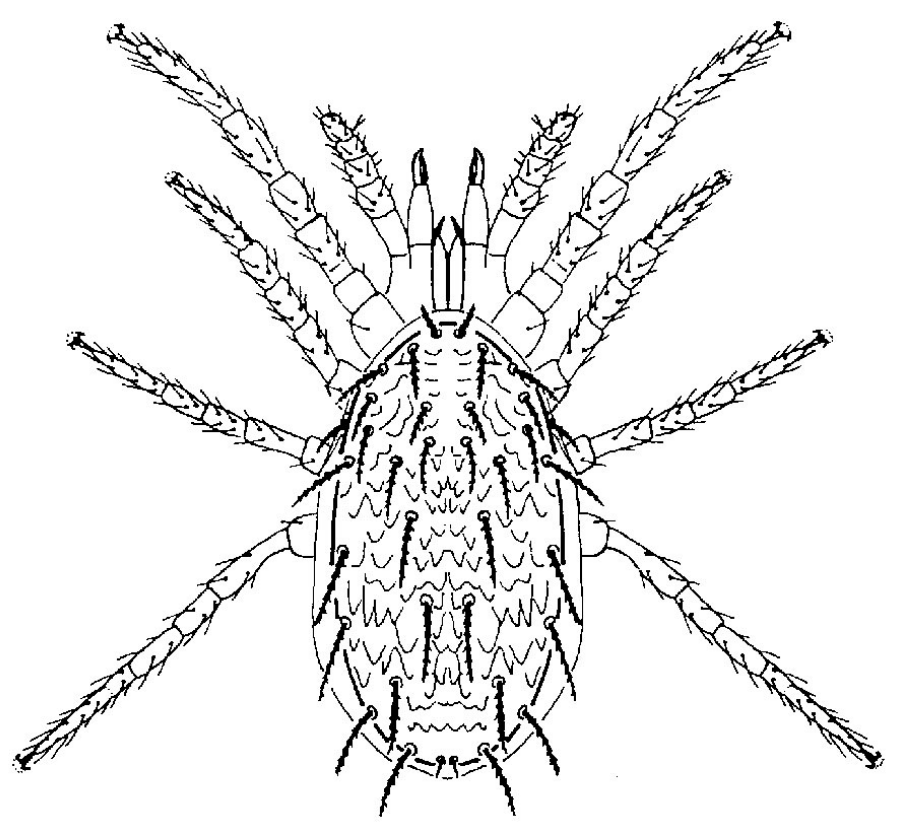

Figure 14. Un ácaro Phytoseiido adulto. Credits: U. S. Department of Agriculture 


\section{Compra de enemigos naturales} para liberación

Los productores de follajes de invernadero, flores y cultivos de vegetales, algunas veces aumentan el control biológico a través de la compra de depredadores y parasitoides. Ocasionalmente esto también lo hacen los productores agrícolas a campo abierto de Florida. La producción de fresas es un ejemplo excelente de un cultivo donde esta práctica es exitosa. Los jardineros caseros frecuentemente preguntan sobre cómo suplementar el control biológico natural en su jardín o terreno.

Existen muchas fuentes comerciales de donde conseguir enemigos naturales. Sin embargo la calidad varía entre productores así que el comprador debe considerar distribuidores que han estado en el negocio por varios años. Una lista detallada de distribuidores se encuentra en la página web sobre control biológico del California Department of Food and Agriculture. http://www.cdpr.ca.gov/docs/ ipminov/bensuppl.htm

La selección de un enemigo natural para la compra es más exitosa si los hábitos y hábitat de los enemigos naturales coinciden con las caractéristicas de la plaga. Por ejemplo, los huevecillos del parasitoide Trichogramma comúnmente sirven para palomillas; los ácaros depredadores del género Phytoseiulus para otros ácaros plaga; los ácaros depredadores del género Neoseiulus (Amblyseius) para thrips y otros ácaros; las mariquitas del género Cryptolaemus para cochinillas y escamas, la chinche espinuda para orugas y crisopas, así como cecidomíidos del género Aphidoletes para áfidos. No así otras mariquitas y mantis religiosas que usualmente no son exitosas. Para productores comerciales, lo mejor es obtener asistencia junto con el producto.
Otras fuentes de información

Otras excelentes fuentes de información incluyen libros tales como:

- Natural Enemies Handbook, University of California Pub. 3386, 154 pp (1998)

- Natural Enemies of Vegetable Insect Pests, Cornell Extension Pub.. 48 pp. (1993)

Ilustraciones de algunos de los enemigos naturales en Florida se pueden encontrar en:

- http://edis.ifas.ufl.edu/ TOPIC_Beneficial_Organisms_and_Beekeeping

Otros sitios de internet que son útiles incluyen:

- A guide to natural enemies by Cornell University http:// www.nysaes.cornell,edu/ent/biocontrol

- Nematodes for biological control by University of Nebraska http://www.ianr.unl.edu/ianr/plntpath/nematode/ wormepns.htm

- Association of Biocontrol Producers http://www.anbp.org

- Featured creatures: profiles of pest and beneficial insects from University of Florida http://creatures.ifas.ufl.edu/ 